\title{
Music Therapy Decreases Anxiety of Patients Undergoing Hematopoietic Stem Cell Transplantation (Controlled Randomized Study)
}

\author{
Carlos Antonio Dóro ${ }^{1 *}$, José Zanis Neto² ${ }^{2}$ Rosemyriam Cunha ${ }^{3}$ and Maribel Pelaez Doro ${ }^{4}$ \\ ${ }^{1}$ Faculty of Arts of Paraná, Federal University of Paraná, Brazil \\ ${ }^{2}$ Department in Hematology, Federal University of Parana, Brazil \\ ${ }^{3}$ Faculty of Arts of Paraná, Federal University of Paraná, Brazil \\ ${ }^{4}$ Department of Clinical Psychology, Psycho-Oncology, Hematology, Federal University of Paraná, Brazil
}

Received: 眥 July 26, 2018; Published: 些 August 16, 2018

*Corresponding author: Carlos Antonio Dóro, Researcher, Musician and Music Therapist: Carlos Antonio Dóro, Degree in Music Therapy of the Faculty of Arts of Paraná (1999), Master's Degree of the Post-Graduate Program in Internal Medicine Of the Complex of Hospital de Clínicas of the Federal University of Paraná (2016), Brazil

\section{Abstract}

Background: Hematopoietic Stem Cells Transplantation (HSCT) is a treatment realized to combat several neoplastic hematological diseases. This proceeding combines chemotherapy doses, radiotherapy and has a high level of toxicity which causes physical and physiological morbidities and psychological suffering to the patient.

Methods: Objective - This study evaluates the impact of music therapy in anxiety expression in adult patients who were hospitalized to go under allogeneic hematopoietic stem cell transplantation (HSCT).

Design: This study is categorized as a Randomized Controlled Trial. Participants: adult Patients ( $\mathrm{n}=100)$; groups: Experimental Music therapy Group (EMG) adult patients $n=50$ Control Group (CG) patients $n=50$.

Intervention: emotional disorders, altered cognition, leading the patient to a depression. In this context, music therapy was applied as a therapeutic resource that contributes with the patient's interaction. After, each music therapy session a Visual Analog Scale (VAS) was applied.

Main Outcome Measure: Student tests for independent variables and Mann-Whitney for non-parametrical variable. The level of statistical significance adopted in all the scales was $\mathrm{p}<0,05$.

Results: The variable anxiety were, analyzed considering three studies: first session, last session and average session of music therapy sessions. $(\mathrm{p}=<0,001)$ in the comparison of the two groups was considered statistically significant.

Conclusion: In this study the music therapy proved to be a strong ally in the treatment of patients undergoing allogeneic hematopoietic stem cells transplantation, decreases anxiety, providing bio-psychosocial welfare.

Keywords: Music therapy; Anxiety; HSCT Allogeneic

\section{Introduction}

The theme of this research is music therapy intervention in adult patients undergoing the allogeneic hematopoietic stem cell transplantation (HSCT Alo) procedure. The research was carried out in the Bone Marrow Transplant Service (STMO) of the Clinical Hospital Complex in the Federal University of Paraná, located in Curitiba, Paraná, Brazil.According to [1], studies have shown that hematopoietic stem cell transplantation (HSCT) has advanced, especially in recent decades, as an important method of treatment for hematologic, oncological, hereditary and autoimmune diseases resulting in higher survival rates. The purpose of (HSCT) is to eradicate various neoplastic hematologic, congenital, genetic or acquired disorders. However, this procedure combines high doses of chemotherapy and/or radiotherapy, with a high degree of cytotoxicity. Points out that organic, lung and heart toxicity, osteoporosis, infections, cataracts and infertility, and that (HSCT) cause's loss of quality of life (QOL), especially in the first hundred days after the transplant period [2].

\section{Also Stressed the Issue of Toxicity}

Pulmonary complications, risks associated with toxic drugs, veno-occlusive disease, graft versus host disease (GVHD), infection, dysfunction and other organs are common [3]. Apart from these adverse effects the patient faces social isolation, in which case the process of psychological functioning suffers significant changes, like emotional disorders, anxiety, mood disorders, reduced affect display and altered cognition and lead him/her to depression. 


\section{Highlights the Fragility of the Patient in Facing a Malignant Disease that Threatens his/her life Resulting in Physical, Social and Emotional Changes}

Coping with threatening life diseases, from diagnosis to more advanced stages, causes drastic changes in the path of human existence caused by the severity of the situation and of the treatment itself, i.e. physical impairments, social changes and emotional breakdown [4]. To begin the preparation or conditioning for transplantation catheter insertion is required, which is a surgical procedure. In the perception of the patient the catheter insertion is an invasive procedure that causes pain, suffering, insecurity, anxiety, and the constant fear of death. It causes a process of emotional and cognitive vulnerability, insecurity, fear, and consequently, the possibility of depression symptoms.

\section{Affirms that the Disease Affects the Whole Psychological System of the Patient}

Currently it is recognized that the disease affects not only the physical dimension, but also reflects on the psychological state of the individual, his/her level of independence, and social relations, factors that go beyond the object of health in traditional medicine [5]. The conditioning regimen involves the application of high-dose chemotherapy and or radiation therapy associated or not to total body irradiation (TBI). At this stage patients are already in solitary confinement, suffering a drastic change in their daily life, entering into a kind of exile from their social and cultural environment, because they need to distance themselves from family, friends, study, work and leisure, losing part of their functionality and autonomy, and different actions in their social relations. They will be required to take extreme care with oral and body care.

Their diet will change dramatically, suffering the side effects of the application of high doses of chemotherapy or radiation therapy, and/or total body irradiation (TBI), which will result in alopecia (hair loss), change in their body image, and loss of identity, causing undesirable side effects, such as nausea, vomiting, diarrhea, fatigue, fever, headache, loss of appetite, and mucositis. In addition to these symptoms, solitary confinement results in psycho-emotional effects, such as, depression, high levels of stress, pain, insecurity, insomnia and, consequently, anxiety and mood disorders. Considering all these stressors experienced by patients during the HSCT procedure, live music sessions were applied through the techniques of music therapy in order to assess the dependent variables of anxiety, and also to check if music therapy can decrease anxiety. Music therapy is a non-invasive intervention resulted in presence, acceptance, and the musical experience, reconnecting the patient to his/her socialcultural-sound environment.

The musical action enabled the patient to rescue the emotional balance, providing relaxation and consequently reducing the feeling of confinement. So, music therapy was shown to be a strong power of action in humans making it an alternative and complementary treatment, contributing to hospital humanization and assisting in other therapeutic interventions.

\section{Material and Methods}

\section{Study Design}

It is a randomized controlled trial

\section{Place}

Clinical Hospital Complex of the Federal University of Paraná, Bone Marrow Transplant Service. Population: Adult patients undergoing allogeneic hematopoietic stem cell transplantation (AlloHSCT). Approved by the ethics committee in the research of the University Federal of Paraná at the Clinical Hospital Complex under Certificate of Ethical Presentation and Appreciation (CAAE) number 26 404414.9.0000.0096 and Registered in Clinical Trials NCT 02639169.

\section{Sample Calculation}

The calculation of the sample size was based on a previous pilot study for which an average of 5.4 was identified for the anxiety and mood score with a standard deviation of 1.9. It was felt that this group corresponded to the control group of the new study, and a minimal difference in the anxiety and mood score of 1 point higher in the Experimental group would be clinically relevant. For a significance level of $5 \%$ and a test power of $80 \%$, it would require at least 45 cases in each group (Control Group and Experimental Music therapy Group). Considering that the evaluation of anxiety and mood score is given by an ordinal scale, a $10 \%$ increase was suggested in the sample size in each group. Thus, 50 patients were needed in each group.

\section{Randomization}

A random and concealed allocation was made of patients in the groups as follows: one contributor not involved with the research threw a dice and communicated the number on the face to the researcher. If the number was even they would make up the experimental music therapy group. If it was odd they would make up the control group. The evaluation was made by an external psychology student. For musical intervention it was not possible to apply the doubleblind principle. The interventions were applied twice a week on Tuesdays and Thursdays from 9:00 am to 12:00 am. The assessment was made after the end of the session music therapy.

\section{Inclusion Criteria}

The invitation was made to each patient submitted to (AlloHSCT), between 18 and 65 years of age, if the patient accepted to participate in the research, he/she would then have to sign a free, prior and informed consent form (FPIC).

\section{Exclusion Criteria}

All patients who did not undergo allogeneic transplantation, those under 18 years of age, and those not willing to participate in the research, were excluded.

\section{Method}

Use live music, through music therapy methods and techniques, provided by a qualified music therapist, performing popular songs that are part of the social-musical-cultural identity of the patient. For example, the music therapist and patient sing together the latter's preferred songs with guitar accompaniment, with the patient following the rhythm of the music playing percussion instruments such as: bongo, tambourine, bells, triangle or maracas, among others, in an interactive process, using music therapy 
techniques such as: renditions of popular songs chosen by patients with singing and improvisation with rhythmic production activities. The sessions were individual and took place in the room beside the patient's bed, twice a week, on Tuesdays and Thursdays, with each session in the Experimental Music Therapy Group lasting thirty minutes.

A one-hour session would be ideal, but due to bone marrow aplasia conditions (i.e., low immunity) this would cause excessive fatigue in patients.

Through an earlier pilot study, it was found that one hour per week, divided into two 30-minute sessions, one on Tuesday and another on Thursday, would be more appropriate given the patients' conditions. Live music has tremendous power to energize patients and provides greater emotional impact. In addition, the human presence of the music therapist results in patients feeling welcome, clinical listening, attention, resonance and enhancement of the interactive expressions of the patient. Anxiety level in the Experimental Music Therapy Group (EMG) was measured using a visual analogue scale (VAS), immediately before and after the music therapy session. Apply the visual analog scale (VAS) to measure the level Anxiety in the Control Group (CG) that not received the music therapy intervention.

\section{Material}

Visual Analog Scale (VAS) [6] was used to assess the dependent variable anxiety. It was collected quantitative data regarding the subjective responses of patients to visual analog scale (VAS) applied before and after the intervention in EMG. And the data collected also in the CG did not receive music therapy intervention. Visual analog scale (VAS), is a numerical scale ranging from 0 to 10 , it is widely used to measure the intensity of pain, but also can be used to measure, breathlessness, anxiety, fatigue, and moods. Operating range anxiety $=0$ "without anxiety", anxiety $=10$ "extreme anxiety". Demographic Questionnaire Clinical It was also collected personal data and clinical patient demographics, such as name, address, age, sex, religion, Education, Social Class. Questionnaire of music therapy to collect musical information musical preferences the family, and patients. Possession of musical information the music therapist preparing a unique repertoire for each patient, and Thus begins the process of the sessions interventions production of live music by the methods of music therapy recreation of songs and improvisation with rhythmic production activities. Informed Consent Form (ICF) All patients signed an informed consent form [7].

\section{Results}

For a description of the quantitative variable the average statistics, mean, minimum, maximum and standard deviation were considered. For the summarization of the qualitative variable, frequencies and percentages were considered. To compare the two groups (EMG and CG) in relation to the quantitative variable the $\mathrm{t}$ test was considered for independent and nonparametric MannWhitney samples. To evaluate the homogeneity of the groups in relation to the distribution of scores of qualitative variables the Chi-square test was considered. Values of "P" less than 0.05 were considered statistically significant. The data was analyzed using the IBM computer program SPSS V.20.

\section{Evaluation of Homogeneity of Groups with Respect to Demographic and Clinical Variables}

For each of the qualitative variables analyzed, we tested the null hypothesis of equal distribution of ratings in both groups versus the alternative hypothesis of different distributions (Table 1).

Table 1: Comparison of experimental music therapy group and control group in relation to assessments of anxiety.

\begin{tabular}{|c|c|c|c|c|c|c|}
\hline \multirow[t]{2}{*}{ Variábles } & \multirow[t]{2}{*}{ Classification } & \multicolumn{2}{|c|}{$\begin{array}{l}\text { Control Group } \\
(n=50)\end{array}$} & \multicolumn{2}{|c|}{$\begin{array}{l}\text { Experimental Music Therapy Group } \\
\qquad(\mathrm{n}=50)\end{array}$} & \multirow[t]{2}{*}{ Value of $p^{*}$} \\
\hline & & $\mathbf{n}$ & $\%$ & $\mathbf{n}$ & $\%$ & \\
\hline Age (average $\pm \mathrm{dp}$ ) & years & \multicolumn{2}{|c|}{$32,6 \pm 10,4$} & \multicolumn{2}{|c|}{$34,1 \pm 11,1$} & 0,488 \\
\hline \multirow[t]{2}{*}{ Gender } & Female & 22 & $44 \%$ & 23 & $46 \%$ & \\
\hline & Male & 28 & $56 \%$ & 27 & $54 \%$ & 0,841 \\
\hline \multirow[t]{2}{*}{ Social Class } & Low & 8 & $16 \%$ & 12 & $24 \%$ & \\
\hline & Average & 42 & $84 \%$ & 38 & $76 \%$ & 0,317 \\
\hline \multirow[t]{2}{*}{ Religion } & Catholic & 37 & $74 \%$ & 32 & $64 \%$ & \\
\hline & Evangelical & 13 & $26 \%$ & 18 & $36 \%$ & 0,28 \\
\hline \multirow[t]{3}{*}{ Education } & 1st degree & 13 & $26 \%$ & 13 & $26 \%$ & \\
\hline & 2nd degree & 21 & $42 \%$ & 19 & $38 \%$ & \\
\hline & 3rd degree & 16 & $32 \%$ & 18 & $36 \%$ & 0,897 \\
\hline \multirow[t]{2}{*}{ Allogeneic } & Akin & 30 & $60 \%$ & 27 & $54 \%$ & \\
\hline & not Akin & 20 & $40 \%$ & 23 & $46 \%$ & 0,545 \\
\hline \multirow[t]{2}{*}{ Source cells } & Bone Marrow & 35 & $70 \%$ & 39 & $78 \%$ & \\
\hline & peripheral blood & 15 & $30 \%$ & 11 & $22 \%$ & 0,661 \\
\hline
\end{tabular}

*Student $\mathrm{t}$ test for independent samples and Chi-square test for qualitative variables; $\mathrm{p}<0.05$ 


\section{Analysis of the First Session}

Table 2 shows the distribution of comparative analysis between the two groups regarding the variable: anxiety, the first music therapy session. It is observed that the difference of the data analyzed statistical significance between the EMG and the CG, with respect to the variable investigated.

Table 2: Distribution of comparative analysis between two groups in relation to variable: anxiety in the first session music therapy

\begin{tabular}{|c|c|c|c|c|c|c|c|c|}
\hline Variable & Group & N & Average & Median & Minimum & Maximum & $\begin{array}{c}\text { Standard } \\
\text { Desviation }\end{array}$ & $\mathbf{p}^{*}$ \\
\hline ANXIETY & EMG & 50 & 2,3 & 2 & 0 & 9 & 2,5 & 0,001 \\
\hline & CG & 50 & 4,6 & 5 & 0 & 10 & 3,1 & \\
\hline
\end{tabular}

$\left(^{*}\right)$ Nonparametric Test Mann-Whitney; $\mathrm{p}<0.05$

\section{Analysis of The Last Session}

Table 3 It is observed that the comparative analysis between

Table 3: Distribution of comparative analysis between two groups in relation to variable: anxiety in the last session music therapy.

\begin{tabular}{|c|c|c|c|c|c|c|c|c|}
\hline Variable & Group & N & Average & Median & Minimum & Maximum & $\begin{array}{c}\text { Standard } \\
\text { Desviation }\end{array}$ & $\mathbf{p}^{*}$ \\
\hline Anxiety & EMG & 50 & 2,5 & 2 & 0 & 9 & 2,5 & 0,002 \\
\hline & CG & 50 & 4,3 & 4 & 0 & 9 & 2,9 & \\
\hline
\end{tabular}

$\left(^{*}\right)$ Nonparametric Test Mann-Whitney; $\mathrm{p}<0.05$

\section{Analysis of The Average of The Sessions}

Table 4 In this table, we can observe the distribution of comparative analysis between the two groups with respect to variable anxiety of the average music therapy sessions. It is observed that the difference between groups with respect to anxiety $(\mathrm{p}<0.001)$ the difference is statistically significant. Data presented in Table a below.

Table 4: Distribution of comparative analysis between two groups in relation to variable: anxiety in average music therapy sessions.

\begin{tabular}{|c|c|c|c|c|c|c|c|c|}
\hline Variable & Group & $\mathbf{n}$ & Average & Median & Minimum & Maximum & $\begin{array}{c}\text { Standard } \\
\text { Desviation }\end{array}$ & Value $\mathbf{p}^{*}$ \\
\hline \multirow[t]{2}{*}{ Anxiety } & EMG & 50 & 2,4 & 2,3 & 0 & 7 & 1,8 & 0,002 \\
\hline & CG & 50 & 4,4 & 4,7 & 0 & 8 & 2,0 & \\
\hline
\end{tabular}

$\left(^{*}\right)$ Nonparametric Test Mann-Whitney; p <0.05

\section{Discussion}

The patient with neoplastic hematologic disease goes through great emotional, physical, psychological and social distress. It was observed that patients experience a lot of anxiety, disorders, nausea, insomnia, and fear of death. The impact of music therapy on anxiety control enables changes; according to reports from patients, some forgot the pain when they were involved in the music therapy. Others said that they did not feel any nausea after the music therapy session, and other patients confessed they had slept better and had dreamed that they were singing. Some also reported that certain songs kept resonating in their mind for days and hours, and we even observed that some intubated patients, who were not able to speak, got emotional, tears rolling down your face during the musical performance, and the parametric device showed a decrease in their heart beats. Music therapy interventions enabled the reduction of symptoms, side effects of the treatment, redeeming the socio-cultural-sound contact, through the recreation of songs, their cultural environment and reducing the feeling of social confinement imposed by the (AlloHSCT) procedure.

In this randomized experimental trial, the visual analog scale (VAS) was used to assess the dependent variable anxiety, which showed a statistically significant decrease in anxiety. Live music applied by a professional music therapist through music therapy methods and techniques offer greater energetic power impact on the patient in relation to recorded music. The presence of the professional in interactive activity with the patient, singing and playing an instrument, percussion and accompanying himself on the guitar, listening to their musical expressions and giving emphasis to the patient's experience, this provides presence and care.

\section{Conclusion}

The music therapy intervention promotes a positive impact on anxiety, and the patients reported decreased anxiety, nausea, improved sleep and mood, there were also some cases of pain relief. This study presentel imitations; however; the music therapy proved to be a strong ally in the treatment of patients undergoing allogeneic hematopoietic stem cells transplantation, decreases anxiety providing bio-psychosocial welfare.

\section{Acknowledgement}

All patients who agreed to participate of their own free will, in this research, without which it would not have been possible. The Bone Marrow Transplant Service of Clinical Hospital of the Federal University of Paraná, for the opportunity granted. Dr. Marister Malvezzi, for believing in music therapy and supporting this research. Prof. Dr. José Zanis Neto for contributing with his knowledge in the tutoring. Prof. Dr. Rosemyrian Cunha, for her contribution and co-tutoring. Psychologist Dr. Maribel Pelaez Dóro for her support and co-tutoring. Dr. Marcia Olandoski for the 
statistical guidance and a special thanks to Ms. Julita Pelaez for her collaboration and statistical guidance. Alírio Pfifer, for encouraging this project and sponsoring the purchase of musical instruments, donating them to the Bone Marrow Transplant Service of Hospital de Clínical of the Federal University of Paraná (UFPR).

\section{References}

1. Ortega ET T, Kojo TK, DE Lima DH, Veran MP (2004) Nursing Compendium on Hematopoietic Stem Cell Transplantation Publisher Curitiba May [Compêndio de Enfermagem em Transplante de CélulasTronco Hematopoéticas Editora Maio Curitiba 2004].

2. Ratcliff CG, Prisloo S, Richardson M, Laura Baynham-Fletcher, Richard Lee, et al (2014) Music Therapy for Patients Who Have Undergone Hematopoietic Stem Cell Transplantation Journal Articles: College of Nursing.

ISSN: 2574-1241

DOI: $10.26717 /$ BJSTR.2018.08.001593

Carlos Antonio Dóro. Biomed J Sci \& Tech Res

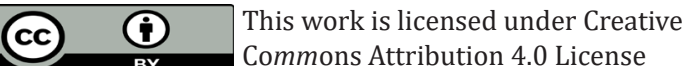

Submission Link: https://biomedres.us/submit-manuscript.php
3. Machado LN, Camandoni VO, Haro leal KP, Moscatello (2009) ELM Bone Marrow Transplant a Multidisciplinary approach [Transplante de Medula Ossea uma abordagem Multidiciplinar] São Paulo Lemar.

4. Petersen EM (2012) Journal of University Hospital Pedro Ernesto [Jornal do Hospital Universitario Pedro Ernesto] UERJ.

5. Machado LN, Camandoni VO, Haro Leal KP, Moscatello (2009) ELM Bone Marrow Transplant a Multidisciplinary approach [Transplante de Medula Ossea uma abordagem Multidiciplinar] São Paulo Lemar.

6. Rubbo AB (2010) Visual Analogue Scale in the evaluation of the intensity of independent bariatric surgery for postoperative pain analgesics Doctoral thesis São Paulo.

7. Bradt J, Dileo C, Grocke D, Magill L (2015) Music Interventions for Improving Psychological and Physical Outcome in Cancer Patients ,The Cochrane Collaboration. Published by John Wiley \& Sons, Ltd.

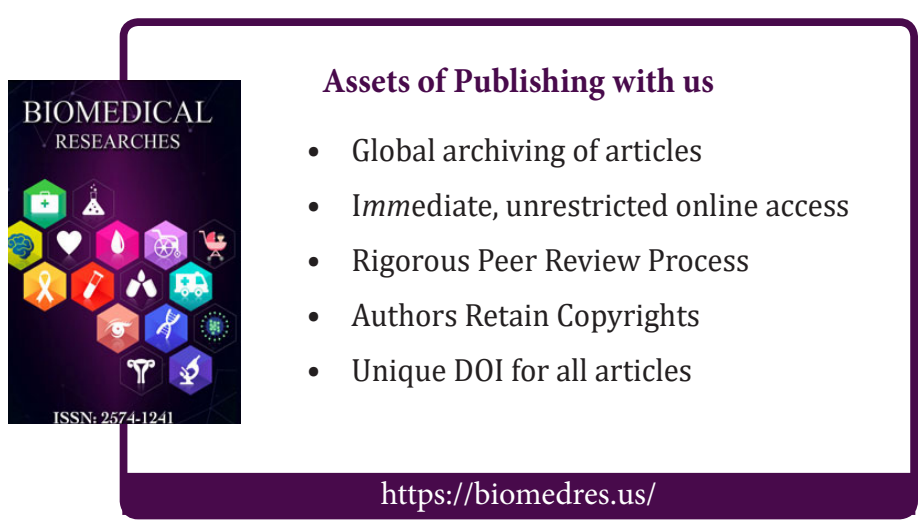

